"noviol C," transmit a little more light and exclude a little more of the ultraviolet rays. With glasses of this class the ultraviolet of ordinary artificial illuminants, or sunlight even at high altitudes can be rendered harmless.

When, however, it is necessary to face a source of ultraviolet and visible rays of high intensity, with a proportion of heat rays as in electric or oxyacetylene welding a difierent problem is encountered. To meet this situation glasses that interrupt a large part of both the visible and the ultraviolet rays, and to some extent the infrared are needed. The supply of such glass is apparently not yet so well worked out and standardized as is the case for the other kinds of protection. But various "black," dark purple-red, and yellow glasses combine these qualities in high degrees. They are not likely to be prescribed by the oculist, but are known chiefly to those who may need to use them in work requiring exposure to intense light sources.

Much remains to be done in the direction of testing different kinds of glass that may be put forward, as to their transparency to various radiations. Much also remains to be done to set forth in clear readily understandable terms the results already arrived at. Such needed advances will be stimulated if ophthalmologists generally study the subject carefully, and begin to formulate their demands more definitely than they have done heretofore. To procure and carefully study the publications of the Bureau of Standards setting forth the results of such tests "Technologic papers No. 93 and No. 119" is a good start to make in that direction.

E. J.

\section{THE MOORFIELDS APPEAL}

Below will be found a statement which must surely touch a responsive chord in the hearts of the majority of our readers. American ophthalmologists are few, who in their travels and studies abroad, have not visited or labored within the hospitable walls of "Moorfields," either of the old building near the Liverpool Station or on the City Road.

Ever since 1804 , when it was founded by Saunders mainly for the relief of that terrible trachoma brought by returning troops from the Egyptian campaign, until the present day, Moorfields has freely furnished the English speaking profession thruout the world with unsurpassed facilities and opportunities for the study of our specialty in all its branches. The long list of attending surgeons of the Royal London Ophthalmic Hospital not only includes many of the most distinguished teachers of British ophthalmology, but its roster of clinical assistants and house surgeons bears the names of many a brilliant ophthalmologist from this side of the Atlantic.

Let us, then, show our appreciation of the good work done by this admirable institution by contributing generous checks, either direct to the Committee, or thru the Editor of this Journal, who will be glad to receive and forward them to the proper official.

$$
\text { C. A. W. }
$$

\section{CORRESPONDENCE}

\section{THE ROYAL LONDON OPH- THALMIC HOSPITAL}

This Hospital, established 116 years ago, and best known thruout the civilized world by its popular name "The Moorefields Eye Hospital," is the parent of all similar institutions thruout the English speaking world.

In 1811 Dr. Edward Delafield and Dr. J. Kearney Rodgers, then young men who had recently graduated in medicine at the College of Physicians and Surgeons in New York, came to London and studied at this Hospital under Dr. Farre and Mr. Benjamin Travers. On their return to their own country in 1818 , so impressed had they been with all they had seen and learnt at the London Eye Infirmary, as it was then called, that they determined to establish a similar institution in America.

This they succeeded in doing and in 